\title{
MITLER, RÜYALAR, BILINÇDIŞI, EŞ BENLIK VE SINEMA
}

Yazar

Aziz Tamer GÜLER 


\title{
(C) Copyright 2021
}

Bu kitabın, basım, yayın ve satış hakları Akademisyen Kitabevi A.Ş.'ne aittir. Anılan kuruluşun izni alınmadan kitabın tümü ya da bölümleri mekanik, elektronik, fotokopi, manyetik kağıt ve/veya başka yöntemlerle çoğaltılamaz, basılamaz, dağıtılamaz. Tablo, şekil ve grafikler izin alınmadan, ticari amaçh kullanılamaz. Bu kitap T.C. Kültür Bakanhğı bandrolü ile satılmaktadır.

"Karşılaşma" adlı Sinema TV Sanatta Yeterlik- Doktora (Beykent Üniversitesi) tez filminin teorik çalş̧malarından üretilmiştir"

ISBN

978-625-7409-37-7

\section{Kitap Adı}

Mitler, Rüyalar, Bilinçdışı, Eş Benlik ve Sinema

\section{Yazar}

Aziz Tamer GÜLER

ORCID iD: 0000-0001-7839-882X

\author{
Yayın Koordinatörü \\ Yasin DİLMEN
}

Sayfa ve Kapak Tasarımı

Akademisyen Dizgi Ünitesi

\section{Yayıncı Sertifika No}

47518

\section{Baskı ve Cilt}

Vadi Matbaacıllk

\section{Bisac Code}

ART057000

DOI

$\mathrm{xxx}$

\section{GENEL DAĞITIM}

Akademisyen Kitabevi A.Ş.

Halk Sokak 5 / A

Yenişehir / Ankara

Tel: o312 4311633

siparis@akademisyen.com 


\section{IÇiNDEKILER}

GİRIŞ 1

\section{BÖLÜM}

GERÇEKLIKK ve SİNEMA............................................................... 5

1.1. SİNEMADA GERÇEKLIIĞIN TEMSILİ ............................................

\section{BÖLÜM}

BİLİNÇ, BİLİNÇDIŞI VE BİLİNÇALTI...................................... 13

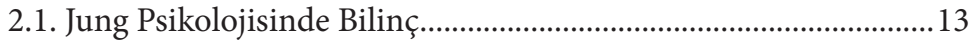

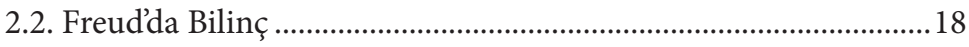

2.3. Freud ve Jung Dışında Bilinç ............................................................... 19

2.4. Bilinçaltı/ Bilinçdışı.............................................................................. 20

\section{BÖLÜM}

RÜYALAR, MİTLER VE SINNEMA ......................................... 33

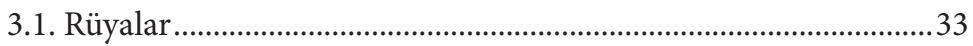

3.2. Mitler Ve Rüyalar ………………………………………………….... 39

3.2.1. Mitolojik Kahraman Örneği: Paris .......................................4 49

3.2.2. Mitolojik Kahraman Örneği: Prometheus..............................51

3.3. Sinemanın Mit, Masal ve Rüyalarla İlişkisi......................................54

3.3.1. Ingmar Bergman Sinemas1 ....................................................60

3.3.2. Andrey Tarkovsky Sinemas1 ....................................................65

3.3.3. Örnek Film Analizi: Siyah Kuğu (Black Swan) .....................70

\section{BÖLÜM}

SINEMA VE ARKETIPLER ...................................................... 75

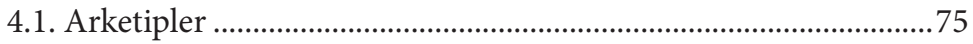

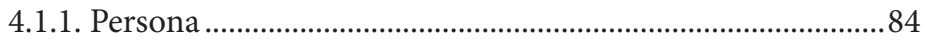

4.1.2. Anima ve Animus ..................................................................... 


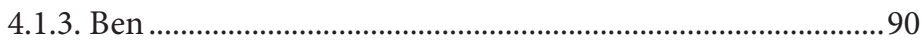

4.1.4. Gölge ve/veya Eş Benlik ........................................................92

SONUÇ ............................................................................ 105

KAYNAKLAR ........................................................... 107

ÖZGEÇMİS ......................................................................................113 


\section{KAYNAKLAR}

Abraham, K (2017). Rüyalar ve Mitler. Çev. E. N. Gökçe. İstanbul: Pinhan Yayıncilik.

Adanır, O (2016). Baudrillard. İstanbul: Say Yayınları.

Adanır O (2012). Sinemada Anlam ve Anlatım. İstanbul: Say Yayınları. Aiskhylos (2013). Zincire Vurulmuş Prometheus. Çev. A. Erhat- S. Eyüboğlu. İstanbul: İş Bankası Kültür Yayınları.

Altay, S., Uğur, U (2018). Sinemada Masalsı Anlatı ve Mitolojik Ögeler: Pan’n Labirenti Filmi. Akademik Sosyal Araştırmalar Dergisi. Y1l: 6, Say1: 72. sayfa:123-141.

Althusser, L (2008). Psikanaliz Üzerine Yazılar: Freud ve Lacan (Felsefi ve Siyasi Yazılar Cilt 3). Çev. İ. Keskinoğlu. İstanbul: İthaki Yayınlari.

Andrei Tarkovski Filmlerinin Felsefi Dayanakları. Kaynak. Taste of Cinema (https://www.filmloverss.com/andrei-tarkovski-filmlerinin-felsefi-dayanaklari/ 29.10.2018. Erişim tarihi: 09.08.2019).

Asiltürk, T. C (2014). Sinemada Yaratıcı Yönetmen, İstanbul: Kalkedon Yayınları.

Bakhtin, M (2001). Karnavaldan Romana- Edebiyat Teorisinden Dil Felsefesine Seçme Yazılar. Çev. C. Soydemir. İstanbul: Ayrıntı Yayınları.

Bakır, B. Ünal Y., Saliji, S (Der.) (2008). Sinema İdeoloji Politika- Sinemasal Yazılar. Ankara: Orient Yayıncilık.

Baudrillard, J (2005). Anahtar Sözcükler. Çev. O. Adanır- L. Yıldırım. Ankara: Paragraf Yayınları.

Baudrillard, J (2010). Sanat Komplosu- Yeni Sanat Düzeni ve Çağdaş Estetik 1, Çev. E. Gen. İstanbul: İletişim Yayıncılık. 
Baudrillard, J (2013). Simülakrlar ve Simülasyon. Çev. O. Adanır. Ankara: Doğu Batı Yayınları.

Bazin, A (2011). Sinema Nedir?. Çev. İ. Şener. İstanbul: Doruk Yayınlari.

Benjamin, W (2019). Hikâye Anlatıcıst- Yalnızlıktan Doğan Masallar. Türkçe Söyleyen E. Arıcan. Ankara: Heretik Basın Yayın.

Benson, N. C (2013). Psikoloji, Çev. A. Yavuz. İstanbul: NTV Yayınları. Bergman'ın Yüzleri, Persona. Fil’m Hafızası Analiz Sinema Yazıları. Erişim 12.08. 2019 https://filmhafizasi.com/bergmanin-yuzleri-persona/

Borges, L. J (2019). Rüyalar Kitabı. Çev. I. Ergüden. 2. Basım. İstanbul: Kırmızı Kedi Yayınevi.

Botz-Bornstein, T (2017). Filmler ve Rüyalar- Tarkovski, Bergman, Sokurov, Kubrick ve Wong Kar-Wai. Çev. C. Soydemir. 3. Basım, İstanbul: Metis Yayınları.

Bowie, M (2007). Lacan. Çev. V. Pekel Şener. Ankara: Dost Kitabevi Yayınları.

Brenner, C (1998). Psikanaliz- Temel Kavramlar. Çev. I. ve Y. Savaşır. Ankara: Hekimler Yayın Birliği.

Büker, S. Topçu, G. Y (2010). Sinema: Tarih, Kuram, Eleştiri. İstanbul: Kırmızı Kedi Yayınevi.

Campbell, J (2010). Kahramanın Sonsuz Yolculuğu. Çev. S. Gürses. 2. Basım, İstanbul: Kabalcı Yayınevi.

Chamisso, von A (2014). Peter Schlemihl'in Olağanüstü Öyküsü. Çev. M. Özbank. İstanbul: Kolektif Kitap.

Coşkun, E (2009). Dünya Sinemasında Akımlar. Ankara: Phoenix Yayinevi.

Darıcı, S (2013). Bilinçaltı Reklamcılık ve İletişim Teknikleri. İstanbul: Gelişim Üniversitesi Yayınları.

Derin, S., Acar V. N (2016). Analitik Terapi Bağlamında Film Analizi. Tehlikeli İlişki. Uluslarararası Sosyal Araştırmalar Dergisi. Cilt: 9, Sayı: 45, Ağustos sayısı. sayfa 449- 460.

Eco, U (2011). Yorum ve Aşııı Yorum. Yayına Hazırlayan: Stefan Collini. Çev. K. Atakay. 5. Basım, İstanbul: Can Yayınları.

Eco, U (2016). Foucault Sarkacı. Çeviren: Şadan Karadeniz. 26. Basım. İstanbul: Can Yayınları.

Eliade, M (2017). Mitler, Rüyalar, Gizemler. Çev. C. Soydemir. İstanbul: Doğu Batı Yayınları.

Erhat, A (1996). Mitoloji Sözlüğü. 6. Basım, İstanbul: Remzi Kitabevi. 
Ertürk, İ (2008). Perde’li Günler, Yönetmenler ve İzlekler Işı̆̆ında Sinema. İstanbul: Yapı Kredi Yayınları.

Film Analizi: Siyah Kuğu (https://dusunbil.com/film-psikanalizi-siyah-kugu/ Erişim tarihi:10.08.2019). H. Hardison. Çev. Ö. M. Urhan. Kaynak: moviepsychoanalyst.blogspot

Fischer, E (2010). Sanatın Gerekliliği. Çev. C. Çapan. 11. Basım, İstanbul: Payel Yayınevi.

Fordham, F (2011). Jung Psikolojisinin Ana Hatları. Çev. A. Yalçıner. İstanbul: Say Yayınları.

Freud, A (2004). Ben ve Savunma Mekanizmaları. Çev. Y. Erim. İstanbul: Metis Yayınları.

Freud, S (2019). Bilinçaltı. Çev. A. N. Yılmaz. Eskişehir: Dorlion Yayınları.

Freud, S (2001). Düşlerin Yorumu. Çev. E. Kapkın. İstanbul: Payel Yayınevi.

Fromm, E (2016). Freud Düşüncesinin Büyüklüğ̈̈ ve Sinırlart- Freud’un Çalışmalarına Genel Bir Bakış. Çev. A. Arıtan. İstanbul: Say Yayınlari.

Fromm, E (2017). Rüyalar, Masallar, Mitler. Çev. A. Arıtan- K. H. Ökten. 3. Basım, İstanbul: Say Yayınları.

Geçtan, E (2017). Psikanaliz ve Sonrası. 16. Basım, İstanbul: Metis Yayınları.

Geçtan, E (1995). Psikodinamik Psikiyatri ve Normaldışı Davranışlar. 12. Basım, İstanbul: Remzi Kitabevi.

Gianvito, J (Der.) (2009). Şiirsel Sinema. Çeviren Ebru Kılıç. İstanbul: Agora Yayınları.

Güçhan, G (1992). C. Metz’in Göstergebilimsel Psikanalitik Yaklaşımı ile Bir Film Çözümleme Denemesi: Bez Bebek. Anadolu Üniversitesi Yayınları: Kurgu. Sayı: 10, Sayfa: 98-114.

Güçhan, G (1990). Christian Metz, Göstergebilim ve Psikanaliz. https://dergipark.org.tr/en/download/article-file/1503989

Gündeş, S (2003). Film Olgusu: Kuram ve Uygulayım Yaklaşımları. İstanbul: İnkılâp Yayınları.

Hall, S. C., Nordby, J. V (2016). Jung Psikolojisinin Ana Çizgileri. Çev. E. Gürol. İstanbul: Cem Yayınevi.

Harari, N. Y (2016). Homo Deus: Yarının Kısa Bir Tarihi. Çev. P. N. Taneli. İstanbul: Kolektif Kitap.

Hoeller, A. S (2004). Bilinmeyen Jung: Carl G. Jung'un Bilinmeyen Gnostik ve Gizemli Dünyası. Çev. S. Soner. İzmir: Ege Meta Yayınları. 
Homeros (2019). İlyada. Çev. A. Erhat. 22. Basım. İstanbul: İş Bankası Kültür Yayınları.

Indick, W (2011). Senaryo Yazarları İçin Psikoloji. Çev. E. Yılmaz- Y.

Karaarslan. 2. Basım. İstanbul: Agora Kitaplığı.

Izod, J (2001). Myth, Mind and the Screen: Understanding the Heroes of our Times. UK: Cambridge University Press.

İnanç, B., E., Yerlikaya E. E (2010). Kişilik Kuramları, Ankara: Pegem Yayınları.

Jacobi, J (2002). C.G. Jung Psikolojisi, Çev. M. Arap. İstanbul: İlhan Yayınevi.

Jung, G. C (2006). Analitik Psikoloji, Çev. E. Gürol. 2. Basım, İstanbul: Payel Yayınevi.

Jung G. C (2016). Analitik Psikoloji Sözlüğ̈̈, Çeviren Nur Nirven. İstanbul: Pinhan Yayınları.

Jung, G. C (2019). Dört Arketip. Çev. Z. A. Yılmazer. 6. Basım. İstanbul: Metis Yayınları.

Jung, G. C (2004). İnsan Ruhuna Yöneliş. Çev. E. Büyükinal. 5. Basım, İstanbul: Say Yayınları.

Jung, G. C (2013). Keşfedilmemiş Benlik. Çev. B. İlhan- C. E. Sılay. 3.Basım. İstanbul: Barış İlhan Yayınevi.

Jung, G. C (2018). Ruh, Çev. İ. H. Yılmaz. 2. Basım, İstanbul: Pinhan Yayıncilik.

Hamilton, E (2010). Mitologya, Çev. Ü. Tamer. 17. Basım, İstanbul: Varlık Yayınları.

Kaçar, E (2018). Lacan ve Topoloji. FLSF (Felsefe ve Sosyal Bilimler Dergisi). http://flsfdergisi.com/ Bahar/Spring, say1/issue: 25, s./ pp.: 535-554. ISSN 2618-5784

Kaplan, B. A (2018). Arketipal Topografyaların Sinematografik Düzlemde İncelenmesi. Konya: Çizgi Kitabevi.

Karakaş, S. Psikoloji Sözlüğü, http://www.psikolojisozlugu.com/conscious-bilinc, Erişim 18.05.19).

Kerényi, C (2012). Prometheus- İnsan Varoluşunun Arketip İmgesi. Çev. T. Türel. İstanbul: Pinhan Yayınları.

Kuspit, D (2006). Sanatın Sonu, Çev. Y. Tezgiden. İstanbul: Metis Yayınlar1.

Lévi- Strauss, C (2013). Mit ve Anlam. Çev. G. Y. Demir. İstanbul: İthaki Yayınları.

May, R (2016). Psikoterapist ve Mitlere Yolculuk. Çev. K. Işık. İstanbul: Okuyan Us Yayınları. 
Mlodinow, L (2013). Subliminal- Bilinçdışı Davranışlarınızı Nasıl Yönetir? Çev. N. Önoğlu. 3. Basım. İstanbul: Okuyan Us Yayınları.

Murphy, J (2019). Bilinçaltının Gücü, Çev. A. Şimşek. İstanbul: Koridor Yayıncilik.

Necatigil, B (2011). Mitologya Sözlüğü, 2. Basım, İstanbul: Sel Yayıncllik.

Nuyan E (2010). Eisenstein ve Tarkovsky'de Sinema Sanatı ve Felsefe, SBE. Felsefe Anabilim Dalı Hacettepe Üniversitesi Yayınlanmamış Doktora Tezi.

Özarslan, Z (Ed) (2015). Sinema Kuramlart- Beyazperdeyi Aydınlatan Kuramcilar. 2. Basım. İstanbul: Su Yayınevi.

Özmen, E (2003). Psikanalizin Serüveni ve Çağrısı. İstanbul: İletişim Yayınları.

Pearson, C. S (2016). İçimizdeki Kahraman. Çeviren Semra Ayanbaşı. 2. Basım, İstanbul: Akaşa Yayınları.

Propp, V (2018). Masalın Biçimbilimi. Çev. M Rifat- S. Rifat. 4. Basım. İstanbul: Türkiye İş Bankası Kültür Yayınları.

Rank, O (2016). Eş Benlik- Bir Psikanaliz Çalışması. Çev. G. Metin. İstanbul: Pinhan Yayıncilık.

Rank, O (2016). Kahramanın Doğuş Miti- Mitolojinin Psikolojik Yoru$m u$. Çev. G. Yavaş. İstanbul: Pinhan Yayıncılık.

Saydam, M. B., Kızıltan, H (2018). Psikomitoloji- İnsanı Öykülerinde Aramak. İstanbul: İthaki Yayınları.

Shakespeare, W. Hamlet. Çev. S. Eyüboğlu. 22. Basım. İstanbul: İş Bankası Kültür Yayınları.

Shakespeare, W (2019). Macbeth. Çev. S. Eyüboğlu. 22. Basım. İstanbul İş Bankası Kültür Yayınları.

Shakespeare, W (2019). Kral Lear. Çev. Ö. Nutku. 13. Basım. İstanbul İş Bankası Kültür Yayınları.

Sharf, S. Richard. Psikoterapi ve Psikolojik Danışma Kuramları, Kuramlar ve Örnek Olaylar. Çev. Ö. H. Avc1. 5. Basım. İstanbul: Nobel Yayınları.

Siyah Kuğu Konusu. Tag Archive. Night's Blog. Ömür Bezci (https:// omurbezci.wordpress.com/tag/siyah-kugu-konusu/ Erişim tarihi 10.08.2019).

Stevens, A (1999). Jung. Çev. A. Çayır. İstanbul: Kaknüs Yayınları.

Stoichita, I. V (2006). Gölgenin Kısa Tarihi. Çev. B. Aydın. Ankara: Dost Yayınevi.

Şenel, G. Z (2015). Ayna Evresi ve Sinema. Libido Dergisi. Yıl 4 Sayı 17. Eylül- Ekim. 
Tarkovsky, A (1992). Mühürlenmiş Zaman. Çev. F. Ant. İstanbul: Afa Yayınları.

Tarkovsky, A (2009). Şiirsel Sinema. Çev. E. Kılıç. İstanbul: Agora Yayınları.

Terbaş, Özcan (Der.) (2019). Sinema ve Psikanaliz, Filmler ve Bilinçdışı.

3. Basım, İstanbul: Bilgi Üniversitesi Yayınları.

Timuçin, A (2009). Sorularla Estetik Elkitabı. İstanbul: Bulut Yayınları. Toptaş, A. H (2017). Gölgesizler. 9-10. Basım, İstanbul: Everest Yayınlari.

Vogler, C (2017). Yazarın Yolculuğu-Senaryo ve Öykü Yazımının Sırları. Çev. K. Şahin. 5. Basım, İstanbul: Okuyan Us Yayınları.

Yalsızuçanlar, S (2014). Rüya Sineması, İstanbul: Palto Yayınevi. 